\title{
Multicenter Study of Carbon-ion Radiotherapy for Oropharyngeal Non-squamous Cell Carcinoma
}

\author{
TAKASHI KANEKO ${ }^{1,2}$, HIROAKI SUEFUJI ${ }^{1}$, MASASHI KOTO ${ }^{2}$, YUSUKE DEMIZU ${ }^{3}$, JUN-ICHI SAITOH ${ }^{4,5}$, \\ HIROSHI TSUJI ${ }^{2}$, TOMOAKI OKIMOTO ${ }^{3}$, TATSUYA OHNO ${ }^{5}$, YOSHIYUKI SHIOYAMA ${ }^{1}$, KENJI NEMOTO $^{6}$, \\ TAKASHI NAKANO ${ }^{7}$, TADASHI KAMADA ${ }^{8}$ and The Japan Carbon-Ion Radiation Oncology Study Group \\ ${ }^{1}$ Ion Beam Therapy Center, SAGA HIMAT Foundation, Tosu, Japan; \\ ${ }^{2}$ QST Hospital, National Institutes for Quantum and Radiological Sciences and Technology, Chiba, Japan; \\ ${ }^{3}$ Department of Radiology, Hyogo Ion Beam Medical Center, Tatsuno, Japan; \\ ${ }^{4}$ Division of Radiation Oncology, Department of Radiology, Faculty of Medicine, \\ Academic Assembly, University of Toyama, Toyama, Japan; \\ ${ }^{5}$ Gunma University Heavy Ion Medical Center, Maebashi, Japan; \\ ${ }^{6}$ Department of Radiation Oncology, Yamagata University Faculty of Medicine, Yamagata, Japan; \\ ${ }^{7}$ Quantum Medical Science Directorate, National Institutes for \\ Quantum and Radiological Sciences and Technology, Chiba, Japan; \\ ${ }^{8}$ Ion-beam Radiation Oncology Center, Kanagawa Cancer Center, Kanagawa, Japan
}

\begin{abstract}
Background/Aim: To evaluate treatment outcomes of carbon-ion radiotherapy for oropharyngeal non-squamous cell carcinoma at four carbon-ion facilities in Japan. Patients and Methods: We retrospectively analyzed the cases of 33 patients with oropharyngeal non-squamous cell carcinoma who were treated with carbon-ion radiotherapy between November 2003 and December 2014. Results: The histology included adenoid cystic carcinoma $(n=25)$ and mucosal malignant melanoma $(n=4)$. No patients had T1 tumors; 23 had T4 tumors. The most-commonly prescribed dose was 57.6 $G y(R B E)$ in 16 fractions. The median follow-up period was 34.8 months (range=4.2-122.8 months). The 3-year local control and overall survival rates were $94.7 \%$ and $90.7 \%$, respectively. There were no grade $\geq 4$ acute adverse events. Only one patient experienced a grade $\geq 4$ late adverse event. No patients experienced late adverse events related to swallowing or salivary function. Conclusion: Carbon-ion radiotherapy appears to be a promising treatment option for oropharyngeal non-squamous cell carcinoma.
\end{abstract}

This article is freely accessible online.

Correspondence to: Dr. Hiroaki Suefuji, Ion Beam Therapy Center, SAGA HIMAT Foundation, 3049 Harakogamachi, Tosu, Saga 8410071, Japan. Tel: +81 942508812, Fax: +81 942811905, e-mail: sufg@saga-himat.jp

Key Words: Carbon-ion radiotherapy, oropharyngeal cancer, nonsquamous cell carcinoma, adverse event, disease control.
Oropharyngeal cancers account for approximately $25 \%$ of cancers of the head and neck (1). Approximately, only $10 \%$ of oropharyngeal cancers are histologically classified as nonsquamous cell carcinomas (SqCC) (2). Due to its rarity, only a few retrospective studies with a small number of patients have assessed its clinical outcomes (3-5). Some previous studies of head and neck non-SqCC, including the oropharynx, suggested that surgical resection with or without postoperative radiotherapy was the best treatment modality, often considered the treatment of choice to achieve a radical cure (6-9). Definitive photon radiotherapy for head and neck non-SqCC showed inferior treatment outcomes when compared to surgical resection with or without postoperative radiotherapy (6-9). An effective treatment strategy for inoperable cases of head and neck non-SqCC has not yet been established.

Compared to photons, carbon-ions are characterized by higher linear energy transfer and greater values of relative biological effectiveness (RBE) (10). Carbon-ions also have better dose localization properties owing to the Bragg peak and small lateral scattering (11). Thus, we may hypothesize that carbon-ion radiotherapy (CIRT) may provide better tumor control and a lower probability of adverse events than photon radiotherapy. A single institutional study of CIRT for locally advanced adenoid cystic carcinoma of the tongue base revealed favorable local control (LC) with acceptable adverse events (12).

By the end of 2014, there were four functional carbon-ion treatment facilities in Japan, namely, the QST Hospital, Hyogo Ion Beam Medical Center, Gunma University Heavy Ion Medical Center, and SAGA-HIMAT Foundation. The 
Japan Carbon-Ion Radiation Oncology Study Group (JCROS) study (1402HN) was a retrospective multicenter analysis of the clinical outcomes of CIRT for head and neck cancers (13-17). The present study was conducted to assess the clinical outcomes of patients with oropharyngeal nonSqCC based on a part of the J-CROS study database.

\section{Patients and Methods}

Ethics. All patients provided informed consent, authorizing the use of their clinical information for research purposes. This study was approved by the institutional review board of each participating institute and was carried out in accordance with the Declaration of Helsinki.

Study participants. This retrospective multicenter study was conducted at the QST Hospital, Hyogo Ion Beam Medical Center, Gunma University Heavy Ion Medical Center, and SAGA-HIMAT Foundation. We analyzed patients with head and neck cancers who received CIRT between November 2003 and December 2014. Detailed inclusion criteria have been described in previous reports (13-17). Patients who had previously undergone radiotherapy for the same lesion were excluded. A total of 908 patients were enrolled in the J-CROS study $1402 \mathrm{HN}$. Among these, 33 patients who received CIRT for oropharyngeal non-SqCC were evaluated for clinical outcomes in this study.

Carbon-ion radiotherapy protocol. The carbon-ion dose is expressed as the photon-equivalent dose in Gy (RBE) and defined as the physical dose multiplied by the carbon-ion RBE. The biological flatness of the spread-out Bragg peak was normalized using the surviving fraction of human salivary gland tumor cells at the distal spread-out Bragg peak region, resulting in an RBE value of 3 (10). The biologically effective dose (BED) was calculated on the basis of a linear-quadratic model assuming an $\alpha / \beta$ ratio of 10 , and the $\mathrm{BED}_{10}$ was used to compare the association between various fractionation doses with the prognostic factors as well as adverse events (18).

The detailed treatment planning has been described in previous reports (13-17). The radiation treatments were planned using a computed tomography (CT)-based three-dimensional treatment planning system at each institution [Original HIPLAN software (NIRS, Chiba, Japan); FOCUS-M (CMS, St. Louis, MO, USA); Xio-M (Mitsubishi Electric, Tokyo, Japan); and XiO-N (Elekta, Stockholm, Sweden and Mitsubishi Electric)]. The target reference dose was prescribed to the isocenter, which was located at the center of the planning target volume (PTV). A more than $90 \%$ isodose line of the prescribed radiation dose covered the entire PTV. No patients underwent prophylactic neck irradiation.

Definition of clinical outcomes. LC was defined as no evidence of tumor regrowth in the PTV, including the PTV margin. Acute and late adverse events were classified according to the Common Terminology Criteria for Adverse Events, version 4.0.

Statistical analyses. All survival times were calculated from the first day of CIRT. LC, progression-free survival (PFS), and overall survival (OS) rates were determined using the Kaplan-Meier method. For univariate analyses, log-rank tests were used to compare the LC, PFS, and OS among subgroups based on age, sex,
Table I. Patient, tumor, and treatment characteristics $(n=33)$.

\begin{tabular}{|c|c|}
\hline Characteristic & $\mathrm{n}(\%)$ or Median (range) \\
\hline Age, yrs & $60(22-79)$ \\
\hline \multicolumn{2}{|l|}{ Gender } \\
\hline Male & $13(39)$ \\
\hline Female & $20(61)$ \\
\hline \multicolumn{2}{|l|}{ Performance status } \\
\hline 0 & $25(76)$ \\
\hline 1 & $8(24)$ \\
\hline \multicolumn{2}{|l|}{ Tumor classification } \\
\hline $\mathrm{T} 2$ & $7(21)$ \\
\hline $\mathrm{T} 3$ & $3(9)$ \\
\hline $\mathrm{T} 4 \mathrm{a}$ & $20(61)$ \\
\hline $\mathrm{T} 4 \mathrm{~b}$ & $3(9)$ \\
\hline \multicolumn{2}{|l|}{ Node classification } \\
\hline No & $27(82)$ \\
\hline N1 & $6(18)$ \\
\hline \multicolumn{2}{|l|}{ Pathological type } \\
\hline Adenoid cystic carcinoma & $25(76)$ \\
\hline Malignant melanoma & $4(12)$ \\
\hline Mucoepidermoid carcinoma & $1(3)$ \\
\hline Basal cell carcinoma & $1(3)$ \\
\hline Basal cell adenocarcinoma & $1(3)$ \\
\hline Myoepithelial carcinoma & $1(3)$ \\
\hline \multicolumn{2}{|l|}{ Tumor status } \\
\hline Naïve & $31(94)$ \\
\hline Recurrence & $2(6)$ \\
\hline $\mathrm{GTV}\left(\mathrm{cm}^{3}\right)$ & $30(6.44-80.7)$ \\
\hline \multicolumn{2}{|l|}{ Protocol dose $\left(\mathrm{BED}_{10}\right)$ : } \\
\hline $\begin{array}{l}\text { 57.6 Gy (RBE)/16 fractions } \\
{[78.3 \mathrm{~Gy}(\mathrm{RBE})]}\end{array}$ & $14(42)$ \\
\hline $\begin{array}{l}\text { 64.0 Gy (RBE)/16 fractions } \\
{[89.6 \mathrm{~Gy}(\mathrm{RBE})]}\end{array}$ & $12(36)$ \\
\hline $\begin{array}{l}\text { 65.0 Gy (RBE)/26 fractions } \\
{[81.3 \mathrm{~Gy}(\mathrm{RBE})]}\end{array}$ & $4(12)$ \\
\hline $\begin{array}{l}70.4 \text { Gy }(\mathrm{RBE}) / 32 \text { fractions } \\
{[85.9 \mathrm{~Gy}(\mathrm{RBE})]}\end{array}$ & $3(9)$ \\
\hline
\end{tabular}

BED: Biologically effective dose; GTV: gross tumor volume; RBE: relative biological effectiveness.

performance status, tumor and node classification, tumor pathological type, gross tumor volume (GTV), and the $\mathrm{BED}_{10}$. $p$ Values $<0.05$ were considered significant, and all statistical tests were two-sided. All statistical analyses were performed using the SPSS software, ver. 23 (IBM, Armonk, NY, USA).

\section{Results}

Patient and treatment characteristics. Patient, tumor characteristics, and treatment details are summarized in Table I. All tumors were staged according to the 7 th edition of the TNM staging system (International Union Against Cancer, 2009). The median patient age was 60 years (range $=22-79$ years). Stage T4a or T4b tumors accounted for $70 \%$ of the tumors. There were various histological types of tumors, with adenoid cystic carcinoma being the most common (76\%). The 


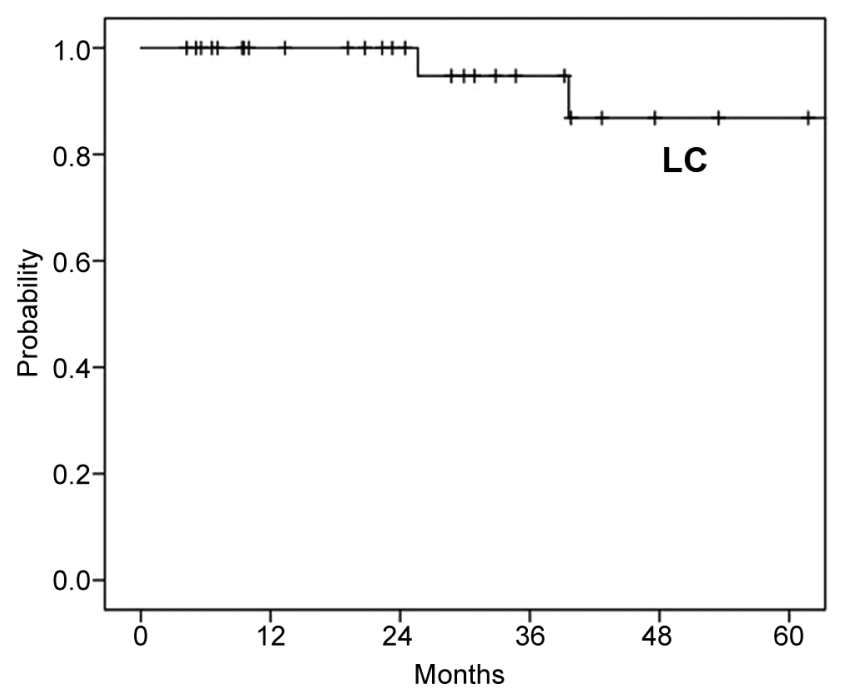

Figure 1. Local control after carbon ion radiotherapy ( $n=33)$. LC: Local control.

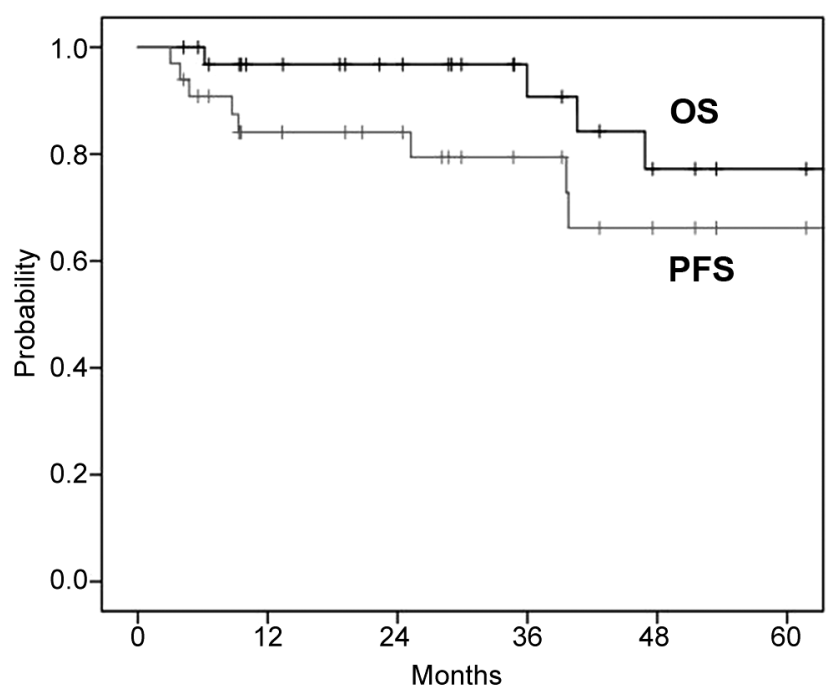

Figure 2. Overall survival and progression-free survival after carbon ion radiotherapy ( $n=33)$. OS: Overall survival; PFS: progression-free survival.

dose and fractionation schedules were decided by each institution. The most commonly prescribed dose was $57.6 \mathrm{~Gy}$ (RBE) in 16 fractions (4 fractions per week), followed by 64.0 Gy (RBE) in 16 fractions (4 fractions per week).

Four patients received chemotherapy. One patient with basal cell carcinoma received docetaxel, cisplatin, and fluorouracil before CIRT, and three patients with mucosal malignant melanoma received concurrent treatment with dacarbazine, nimustine hydrochloride, and vincristine sulfate.
Table II. Univariate analysis for predictors of local control, overall survival, and progression-free survival.

\begin{tabular}{|c|c|c|c|c|}
\hline \multirow[t]{2}{*}{ Factor } & \multirow[t]{2}{*}{$\mathrm{n}$} & \multicolumn{3}{|c|}{$p$-Value } \\
\hline & & $\mathrm{LC}$ & OS & PFS \\
\hline Age, yrs & & 0.114 & 0.047 & 0.169 \\
\hline$<60$ & 15 & & & \\
\hline$\geq 60$ & 18 & & & \\
\hline Gender & & 0.596 & 0.384 & 0.442 \\
\hline Male & 13 & & & \\
\hline Female & 20 & & & \\
\hline Performance status & & 0.195 & 0.002 & 0.023 \\
\hline 0 & 25 & & & \\
\hline 1 & 8 & & & \\
\hline Tumor classification & & 0.431 & 0.956 & 0.596 \\
\hline $\mathrm{T} 2,3$ & 10 & & & \\
\hline $\mathrm{T} 4 \mathrm{a}, 4 \mathrm{~b}$ & 23 & & & \\
\hline Node classification & & 0.495 & 0.816 & 0.693 \\
\hline No & 27 & & & \\
\hline N1 & 6 & & & \\
\hline Pathological type & & 0.355 & 0.317 & 0.427 \\
\hline $\mathrm{ACC}$ & 25 & & & \\
\hline Other & 8 & & & \\
\hline $\operatorname{GTV}\left(\mathrm{cm}^{3}\right)$ & & 0.816 & 0.996 & 0.827 \\
\hline$<30.0$ & 16 & & & \\
\hline$\geq 30.0$ & 17 & & & \\
\hline $\mathrm{BED}_{10}[\mathrm{~Gy}(\mathrm{RBE})]$ & & 0.168 & 0.328 & 0.549 \\
\hline$<85.9$ & 18 & & & \\
\hline$\geq 85.9$ & 15 & & & \\
\hline
\end{tabular}

ACC: Adenoid cystic carcinoma; BED: biologically effective dose; GTV: gross tumor volume; LC: local control; OS: overall survival; PFS: progression-free survival.

Local control and survival analyses. The median follow-up period was 35 months (range $=4-123$ months). Eight patients (24\%) developed recurrence with initial recurrence patterns of distant metastases in seven patients and local+regional recurrence in one patient. Two patients developed local recurrence, with one developing local recurrence after distant metastases. The 3- and 5-year LC rates were 94.7\% (95\% confidence interval $[\mathrm{CI}]=84.7-100.0 \%)$ and $86.8 \%$ (95\%CI=69.4-100.0\%), respectively (Figure 1).

By the last follow-up date, three patients had died of the disease, and one patient had died of treatment-related mucosal hemorrhage. The 3- and 5-year OS rates were 90.7\% $(95 \% \mathrm{CI}=77.9-100.0 \%)$ and $77.2 \% \quad(95 \% \mathrm{CI}=56.7-97.7 \%)$, respectively (Figure 2). The 3- and 5-year PFS rates were $79.4 \%(95 \% \mathrm{CI}=64.4-94.4 \%)$ and $66.2 \%(95 \% \mathrm{CI}=45.3-87.1 \%)$, respectively (Figure 2). Eight patients survived for $>5$ years.

The results of our univariate analyses of prognostic factors for LC, PFS, and OS are shown in Table II. Younger age ( $<60$ years) was a significant good prognostic factor for OS. A good performance status was a significant prognostic 
Table III. Acute (Grade $\geq 3$ ) and late (Grade $\geq 2$ ) adverse events.

\begin{tabular}{lcccc}
\hline Type of adverse event & Grade 2 & Grade 3 & Grade 4 & Grade 5 \\
\hline $\begin{array}{l}\text { Acute events } \\
\text { Mucositis }\end{array}$ & - & 20 & 0 & 0 \\
$\begin{array}{l}\text { Dermatitis } \\
\text { Late events }\end{array}$ & - & 1 & 0 & 0 \\
$\begin{array}{l}\text { Osteonecrosis } \\
\text { of the jaw }\end{array}$ & 4 & 1 & 0 & 0 \\
Mucosal hemorrhage & 0 & 1 & 0 & 1 \\
$\begin{array}{l}\text { Mucositis } \\
\text { Oral fistula }\end{array}$ & 1 & 0 & 0 & 0 \\
$\begin{array}{l}\text { Dysgeusia } \\
\text { Hoarseness }\end{array}$ & 1 & 0 & 0 & 0 \\
\hline
\end{tabular}

factor for both PFS and OS. Tumor classification, tumor size, and pathological type did not show an association with LC, PFS, and OS in the univariate analyses.

Acute and late adverse events. Regarding CIRT-related acute adverse events (grade $\geq 3$ ), grade 3 mucositis was observed in 20 patients $(61 \%)$, and grade 3 dermatitis in 1 patient $(3 \%)$. There were no grade 4 or 5 acute adverse events.

Regarding late adverse events (grade $\geq 2$ ), 1 patient $(3 \%)$ in her 60s with basal cell adenocarcinoma (clinical staging cT4bN0M0, inoperable) died from a grade 5 hemorrhage from an ulcer caused by epithelial destruction due to tumor growth and tumor reduction following treatment. The prescribed dose was $65.0 \mathrm{~Gy}(\mathrm{RBE}) / 26$ fractions, and the period between CIRT initiation and the hemorrhage was 6 months. There were no grade 4 late adverse events. Osteonecrosis of the jawbone was observed in 5 patients $(15 \%)$, grade 2 in 4 patients (12\%), and grade 3 in 1 patient $(3 \%)$ (Table III). No patients experienced grade $\geq 2$ late adverse events related to swallowing or salivary function.

\section{Discussion}

To the best of our knowledge, this is the first multicenter study to assess the clinical outcomes of patients with oropharyngeal non-SqCC. Although non-SqCC is considered a radiationresistant malignancy and higher number of $\mathrm{T} 4$ stage tumors were included in this study, the 3-year and 5-year LC rates were $94.7 \%$ and $86.8 \%$, respectively. Regarding adverse events, no patients experienced grade $\geq 2$ late adverse events related to swallowing or salivary function. However, grade $\geq 3$ dysphagia and grade $\geq 2$ dry mouth was experienced in about $5 \%$ and $30 \%$ patients of oropharyngeal SqCC treated with intensity-modulated radiotherapy with chemotherapy, respectively (19). However, one patient experienced grade 5 hemorrhage from an oropharyngeal epithelial ulcer.
Koto et al. reported a single-institutional study of CIRT for locally advanced adenoid cystic carcinoma of the tongue base; among the 18 patients included in their study, the 5year LC and OS rates were $92 \%$ and $72 \%$, respectively, with acceptable adverse events (12). In our retrospective multicenter study, the 5-year LC and OS rates were $86.8 \%$ and $77.2 \%$, respectively. Regarding treatment outcomes of oropharyngeal minor salivary gland carcinomas based on a population-based analysis of 1,426 patients, about $70 \%$ of patients were treated with surgical resection with or without photon radiotherapy and the 5-year disease-specific survival rate of all patients was reported to be $75.1 \%$ (20). Iyer et al. conducted a single-institution retrospective study in patients with oropharyngeal minor salivary gland carcinomas and reported a 5-year OS rate of $80 \%$ (3); however, the main treatment modality in their study was surgical resection, and only $20 \%$ of the patients had T3 or T4 tumors. Thus, CIRT seems to be an effective treatment strategy for oropharyngeal non-SqCC. The effectiveness of CIRT was also reported for axial bone and soft tissue sarcomas (21).

In our study, 20 of the 33 patients $(61 \%)$ presented with grade 3 radiation mucositis. Musha et al. evaluated the correlation between mucositis and carbon-ion radiation dose in 39 patients treated with CIRT for head and neck carcinoma and reported a threshold of 43.0 Gy (RBE) in 16 fractions for Grade 2-3 acute mucositis (as per RTOG criteria) in the palate (22). In a systematic review of the incidence of mucositis in patients with head and neck carcinoma undergoing photon radiotherapy, $43 \%$ of the patients receiving concurrent chemoradiotherapy and $34 \%$ of those who underwent radiotherapy alone experienced grade 3-4 acute mucositis (23). The incidence of grade $\geq 3$ mucositis was slightly higher for CIRT in our study than for photon radiotherapy noted in the previous report; however, no cases of grade $\geq 4$ or mucositis were observed. An incidence of grade $\geq 3$ acute mucositis of $19 \%$ was reported for CIRT in locally advanced sinonasal malignant tumors (24). We hypothesize that the oropharynx being the tumor site in our study may be the reason for the higher rate of acute mucositis $(61 \%)$ in our study, as it receives physical stimulation when patients eat meals. Since all cases of acute severe mucositis recovered after CIRT, we considered CIRT for oropharyngeal non-SqCCs acceptable.

Regarding late adverse events, five patients developed osteonecrosis of the jaw. In a series of 63 patients with head and neck malignancies treated with CIRT, Sasahara et al. concluded that the risk factors for osteonecrosis of the maxilla included the presence of teeth within the PTV and a maxilla dose volume $>50 \mathrm{~Gy}$ (RBE) in a 16-fraction protocol (25). For photon radiotherapy, several articles also reported the risk factors for osteoradionecrosis (26-28). Tsai et al. reported that maxilla dose volumes $>50$ Gy were risk factors for osteonecrosis in a multivariate analysis (26). It has been 
shown that high-dose irradiation volumes of the jaw in both carbon-ion and photon radiotherapy are risk factors of osteonecrosis (25-27). A trend of a lower incidence of osteonecrosis was observed for intensity-modulated radiotherapy when compared to 2- or 3-dimensional photon radiotherapy $(26,28)$. Intensity-modulated CIRT using spot scanning irradiation may be an effective method to reduce the incidence of osteonecrosis when compared to passive beam irradiation (29). In this study, all patients were treated with passive beam irradiation. It has also been suggested that osteonecrosis develops as a result of gingival regression due to radiotherapy, leading to an environment that is susceptible to bone infection (30). Therefore, periodic dental management and care after treatment may be effective in reducing the risk of osteonecrosis of the jaw.

We observed no grade $\geq 2$ adverse events related to swallowing or salivary function. Boscolo-Rizzo et al. reported that patients treated with radiotherapy for oropharyngeal carcinoma showed a significantly higher rate of adverse events related to teeth, open mouth, dry mouth, and sticky saliva compared with surgical resection (31). Unlike photon radiotherapy, the good dose localization properties of carbon-ions may spare pharyngeal muscles and salivary glands. Moreover, often CIRT for oropharyngeal carcinoma involved only the primary lesions and did not include prophylactic whole neck irradiation, which may explain the preservation of swallowing and salivary function. However, careful long-term follow-up is needed to confirm lower rate of adverse events related to swallowing or salivary function.

Tumor and node classification as well as tumor size have been reported as prognostic factors in cases of oropharyngeal carcinomas that were treated with surgical dissection (32, 33). In photon radiotherapy for hypopharyngeal cancer, Chen et al. reported that a primary gross tumor volume $(\mathrm{GTV})<30$ $\mathrm{cm}^{3}$ was a strong prognostic factor for good clinical outcomes (34). A bulky malignant tumor has a larger hypoxic volume, and photons have a higher oxygen enhancement ratio when compared to carbon-ions (35). These characteristics can lead to photon radio resistance in bulky malignant tumors (35). Unlike previous reports, our univariate analyses did not reveal tumor size or tumor classification as prognostic factors. Carbon-ions are characterized by a higher linear energy transfer and lower oxygen enhancement ratio when compared to photons and therefore may provide a higher probability of bulky tumor control. Therefore, CIRT may be more effective than photon radiotherapy for bulky tumors of the oropharynx.

This study has several limitations. First, it is a retrospective study with a short median follow-up period; moreover, the number of enrolled patients was small. However, oropharyngeal non-SqCC is rare, and there are few reports on treatment outcomes. Second, plural total doses and fractionation protocols for CIRT were included. Third, there were no data on the anatomical subsites of the oropharynx; consequently, it was difficult to perform subgroup analyses by anatomical subsites.

\section{Conclusion}

This is the first multicenter study of CIRT for oropharyngeal non-SqCC. We found that the LC and OS rates of patients undergoing CIRT were comparable to those previously reported for oropharyngeal non-SqCC treated by surgical resection, although our study included a higher number of patients with T4 tumors as compared to the previously published reports. Therefore, CIRT is a promising treatment for oropharyngeal non-SqCC. A future study that includes a larger sample size and longer follow-up is needed.

\section{Conflicts of Interest}

The Authors have no conflicts of interest to disclose in relation to this study.

\section{Authors' Contributions}

Takashi Kaneko performed the statistical analyses, interpreted the data and wrote the manuscript. Hiroaki Suefuji, Masashi Koto, Yusuke Demizu and Jun-ichi Saitoh assembled the data, interpretation and wrote the manuscript. Hiroshi Tsuji, Tomoaki Okimoto, Tatsuya Ohno, Yoshiyuki Shioyama, Kenji Nemoto, Takashi Nakano and Tadashi Kamada designed the study, interpreted the data and wrote the manuscript. All Authors read and approved the final manuscript.

\section{References}

1 Mourad M, Jetmore T, Jategaonkar AA, Moubayed S, Moshier E and Urken ML: Epidemiological trends of head and neck cancer in the United States: A SEER population study. J Oral Maxillofac Surg 75(12): 2562-2572, 2017. PMID: 28618252. DOI: $10.1016 /$ j.joms.2017.05.008

2 Japan Society for Head and Neck Cancer Cancer Registry Committee. Report of Head and Neck Cancer Registry of Japan Clinical Statistics of Registered Patients, 2017. Available at: http://www.jshnc.umin.ne.jp/pdf/HNC_2017report.pdf [Last accessed on May 7, 2021]

3 Iyer NG, Kim L, Nixon IJ, Palmer F, Kraus D, Shaha AR, Shah JP, Patel SG and Ganly I: Factors predicting outcome in malignant minor salivary gland tumors of the oropharynx. Arch Otolaryngol Head Neck Surg 136(12): 1240-1247, 2010. PMID: 21173374. DOI: $10.1001 /$ archoto.2010.213

4 Schoppy DW, Kupferman ME, Hessel AC, Bell DM, Garland EM, Damrose EJ and Holsinger FC: Transoral endoscopic head and neck surgery (eHNS) for minor salivary gland tumors of the oropharynx. Cancers Head Neck 2: 5, 2017. PMID: 31093352. DOI: 10.1186/s41199-017-0024-2

5 Hay AJ, Migliacci J, Karassawa Zanoni D, McGill M, Patel S and Ganly I: Minor salivary gland tumors of the head and neckMemorial Sloan Kettering experience: Incidence and outcomes 
by site and histological type. Cancer 125(19): 3354-3366, 2019. PMID: 31174233. DOI: 10.1002/cncr.32208

6 Vander Poorten V, Hunt J, Bradley PJ, Haigentz M Jr, Rinaldo A, Mendenhall WM, Suarez C, Silver C, Takes RP and Ferlito A: Recent trends in the management of minor salivary gland carcinoma. Head Neck 36(3): 444-455, 2014. PMID: 23559518. DOI: $10.1002 /$ hed .23249

7 Chen AM, Bucci MK, Weinberg V, Garcia J, Quivey JM, Schechter NR, Phillips TL, Fu KK and Eisele DW: Adenoid cystic carcinoma of the head and neck treated by surgery with or without postoperative radiation therapy: prognostic features of recurrence. Int J Radiat Oncol Biol Phys 66(1): 152-159, 2006. PMID: 16904520. DOI: 10.1016/j.ijrobp.2006.04.014

8 Lazarev S, Gupta V, Hu K, Harrison LB and Bakst R: Mucosal melanoma of the head and neck: a systematic review of the literature. Int J Radiat Oncol Biol Phys 90(5): 1108-1118, 2014. PMID: 25539369. DOI: 10.1016/j.ijrobp.2014.03.042

9 Chen AM, Granchi PJ, Garcia J, Bucci MK, Fu KK and Eisele DW: Local-regional recurrence after surgery without postoperative irradiation for carcinomas of the major salivary glands: implications for adjuvant therapy. Int J Radiat Oncol Biol Phys 67(4): 982-987, 2007. PMID: 17241753. DOI: 10.1016/j.ijrobp.2006.10.043

10 Kanai T, Endo M, Minohara S, Miyahara N, Koyama-ito H, Tomura H, Matsufuji N, Futami Y, Fukumura A, Hiraoka T, Furusawa Y, Ando K, Suzuki M, Soga F and Kawachi K: Biophysical characteristics of HIMAC clinical irradiation system for heavy-ion radiation therapy. Int J Radiat Oncol Biol Phys 44(1): 201-210, 1999. PMID: 10219815. DOI: 10.1016/s03603016(98)00544-6

11 Amirul Islam M, Yanagi T, Mizoe JE, Mizuno H and Tsujii H: Comparative study of dose distribution between carbon ion radiotherapy and photon radiotherapy for head and neck tumor. Radiat Med 26(7): 415-421, 2008. PMID: 18769999. DOI: 10.1007/s11604-008-0252-9

12 Koto M, Hasegawa A, Takagi R, Ikawa H, Naganawa K, Mizoe JE, Jingu K, Tsujii H, Tsuji H, Kamada T, Okamoto $Y$ and Organizing Committee for the Working Group for Head and Neck Cancer: Evaluation of the safety and efficacy of carbon ion radiotherapy for locally advanced adenoid cystic carcinoma of the tongue base. Head Neck 38 Suppl 1: E2122-E2126, 2016. PMID: 26854882. DOI: 10.1002/hed.24397

13 Koto M, Demizu Y, Saitoh JI, Suefuji H, Tsuji H, Okimoto T, Ohno T, Shioyama Y, Takagi R, Nemoto K, Nakano T, Kamada $\mathrm{T}$ and Japan Carbon-Ion Radiation Oncology Study Group: Multicenter study of carbon-ion radiation therapy for mucosal melanoma of the head and neck: subanalysis of the Japan Carbon-Ion Radiation Oncology Study Group (J-CROS) study (1402 HN). Int J Radiat Oncol Biol Phys 97(5): 1054-1060, 2017. PMID: 28332989. DOI: 10.1016/j.ijrobp.2016.12.028

14 Sulaiman NS, Demizu Y, Koto M, Saitoh JI, Suefuji H, Tsuji H, Ohno T, Shioyama Y, Okimoto T, Daimon T, Nemoto K, Nakano T, Kamada T and Japan Carbon-Ion Radiation Oncology Study Group: Multicenter study of carbon-ion radiation therapy for adenoid cystic carcinoma of the head and neck: subanalysis of the Japan Carbon-Ion Radiation Oncology Study Group (J-CROS) study (1402 HN). Int J Radiat Oncol Biol Phys 100(3): 639-646, 2018. PMID: 29413278. DOI: 10.1016/j.ijrobp.2017.11.010

15 Saitoh JI, Koto M, Demizu Y, Suefuji H, Ohno T, Tsuji H, Okimoto T, Shioyama Y, Nemoto K, Nakano T, Kamada T and
Japan Carbon-Ion Radiation Oncology Study Group: A multicenter study of carbon-ion radiation therapy for head and neck adenocarcinoma. Int J Radiat Oncol Biol Phys 99(2): 442449, 2017. PMID: 28871995. DOI: 10.1016/j.ijrobp.2017.04.032

16 Shirai K, Koto M, Demizu Y, Suefuji H, Ohno T, Tsuji H, Okimoto T, Shioyama Y, Saitoh JI, Nemoto K, Nakano T, Kamada T and Japan Carbon-Ion Radiation Oncology Study Group: Multiinstitutional retrospective study of mucoepidermoid carcinoma treated with carbon-ion radiotherapy. Cancer Sci 108(7): 14471451, 2017. PMID: 28474791. DOI: 10.1111/cas.13270

17 Suefuji H, Koto M, Demizu Y, Saitoh JI, Shioyama Y, Tsuji H, Okimoto T, Ohno T, Nemoto K, Nakano T and Kamada T: A retrospective multicenter study of carbon ion radiotherapy for locally advanced olfactory neuroblastomas. Anticancer Res 38(3): 1665-1670, 2018. PMID: 29491100. DOI: 10.21873/ anticanres.12399

18 Fowler JF: The linear-quadratic formula and progress in fractionated radiotherapy. Br J Radiol 62(740): 679-694, 1989. PMID: 2670032. DOI: 10.1259/0007-1285-62-740-679

19 Gillison ML, Trotti AM, Harris J, Eisbruch A, Harari PM, Adelstein DJ, Jordan RCK, Zhao W, Sturgis EM, Burtness B, Ridge JA, Ringash J, Galvin J, Yao M, Koyfman SA, Blakaj DM, Razaq MA, Colevas AD, Beitler JJ, Jones CU, Dunlap NE, Seaward SA, Spencer S, Galloway TJ, Phan J, Dignam JJ and Le QT: Radiotherapy plus cetuximab or cisplatin in human papillomavirus-positive oropharyngeal cancer (NRG Oncology RTOG 1016): a randomised, multicentre, non-inferiority trial. Lancet 393(10166): 40-50, 2019. PMID: 30449625. DOI: 10.1016/S0140-6736(18)32779-X

20 Goel AN, Badran KW, Braun APG, Garrett AM and Long JL: Minor salivary gland carcinoma of the oropharynx: a populationbased analysis of 1426 patients. Otolaryngol Head Neck Surg 158(2): 287-294, 2018. PMID: 28971745. DOI: 10.1177/ 0194599817735309

21 Cuccia F, Fiore MR, Barcellini A, Iannalfi A, Vischioni B, Ronchi S, Bonora M, Riva G, Vai A, Facoetti A, Preda L, Valvo F and Vitolo V: Outcome and toxicity of carbon ion radiotherapy for axial bone and soft tissue sarcomas. Anticancer Res 40(5): 28532859, 2020. PMID: 32366434. DOI: 10.21873/anticanres.14260

22 Musha A, Shimada H, Shirai K, Saitoh J, Yokoo S, Chikamatsu $\mathrm{K}$, Ohno $\mathrm{T}$ and Nakano $\mathrm{T}$ : Prediction of acute radiation mucositis using an oral mucosal dose surface model in carbon ion radiotherapy for head and neck tumors. PLoS One 10(10): e0141734, 2015. PMID: 26512725. DOI: 10.1371/journal. pone. 0141734

23 Trotti A, Bellm LA, Epstein JB, Frame D, Fuchs HJ, Gwede CK, Komaroff E, Nalysnyk L and Zilberberg MD: Mucositis incidence, severity and associated outcomes in patients with head and neck cancer receiving radiotherapy with or without chemotherapy: a systematic literature review. Radiother Oncol 66(3): 253-262, 2003. PMID: 12742264. DOI: 10.1016/s01678140(02)00404-8

24 Koto M, Demizu Y, Saitoh JI, Suefuji H, Tsuji H, Okimoto T, Ohno T, Shioyama Y, Ikawa H, Nemoto K, Nakano T, Kamada $\mathrm{T}$ and Japan Carbon-Ion Radiation Oncology Study Group: Definitive carbon-ion radiation therapy for locally advanced sinonasal malignant tumors: subgroup analysis of a multicenter study by the Japan Carbon-Ion Radiation Oncology Study Group (J-CROS). Int J Radiat Oncol Biol Phys 102(2): 353-361, 2018. PMID: 30191869. DOI: 10.1016/j.ijrobp.2018.05.074 
25 Sasahara G, Koto M, Ikawa H, Hasegawa A, Takagi R, Okamoto $\mathrm{Y}$ and Kamada T: Effects of the dose-volume relationship on and risk factors for maxillary osteoradionecrosis after carbon ion radiotherapy. Radiat Oncol 9(1): 92, 2014. PMID: 24708583. DOI: $10.1186 / 1748-717 X-9-92$

26 Tsai CJ, Hofstede TM, Sturgis EM, Garden AS, Lindberg ME, Wei Q, Tucker SL and Dong L: Osteoradionecrosis and radiation dose to the mandible in patients with oropharyngeal cancer. Int J Radiat Oncol Biol Phys 85(2): 415-420, 2013. PMID: 22795804. DOI: $10.1016 /$ j.ijrobp.2012.05.032

27 MD Anderson Head and Neck Cancer Symptom Working Group: Dose-volume correlates of mandibular osteoradionecrosis in Oropharynx cancer patients receiving intensity-modulated radiotherapy: Results from a case-matched comparison Radiother Oncol 124(2): 232-239, 2017. PMID: 28733053. DOI: 10.1016/j.radonc.2017.06.026

28 Aarup-Kristensen S, Hansen CR, Forner L, Brink C, Eriksen JG and Johansen $\mathrm{J}$ : Osteoradionecrosis of the mandible after radiotherapy for head and neck cancer: risk factors and dosevolume correlations. Acta Oncol 58(10): 1373-1377, 2019. PMID: 31364903. DOI: 10.1080/0284186X.2019.1643037

29 Shiomi M, Mori S, Shinoto M, Nakayama Y, Kamada T and Yamada S: Comparison of carbon-ion passive and scanning irradiation for pancreatic cancer. Radiother Oncol 119(2): 326330, 2016. PMID: 27262617. DOI: 10.1016/j.radonc. 2016.04 .026

30 Katsura K, Sasai K, Sato K, Saito M, Hoshina H and Hayashi $\mathrm{T}$ : Relationship between oral health status and development of osteoradionecrosis of the mandible: a retrospective longitudinal study. Oral Surg Oral Med Oral Pathol Oral Radiol Endod 105(6): 731-738, 2008. PMID: 18329913. DOI: 10.1016/ j.tripleo.2007.10.011
31 Boscolo-Rizzo P, Stellin M, Fuson R, Marchiori C, Gava A and Da Mosto MC: Long-term quality of life after treatment for locally advanced oropharyngeal carcinoma: surgery and postoperative radiotherapy versus concurrent chemoradiation. Oral Oncol 45(11): 953-957, 2009. PMID: 19665919. DOI: 10.1016/j.oraloncology.2009.06.005

32 Bastos de Souza TR, Pinto CA, da Cunha Mercante AM, Nishimoto IN, Brasilino de Carvalho $M$ and Kowalski LP: Long-term results of surgical treatment for advanced oropharyngeal squamous cell carcinoma. Head Neck 36(8): 1146-1154, 2014. PMID: 23897725. DOI: 10.1002/hed.23427

33 Dejaco D, Steinbichler T, Schartinger VH, Fischer N, Anegg M, Dudas J, Posch A, Widmann G and Riechelmann H: Prognostic value of tumor volume in patients with head and neck squamous cell carcinoma treated with primary surgery. Head Neck 40(4): 728-739, 2018. PMID: 29272056. DOI: 10.1002/hed.25040

34 Chen SW, Yang SN, Liang JA, Lin FJ and Tsai MH: Prognostic impact of tumor volume in patients with stage III-IVA hypopharyngeal cancer without bulky lymph nodes treated with definitive concurrent chemoradiotherapy. Head Neck 31(6): 709716, 2009. PMID: 19260114. DOI: 10.1002/hed.21011

35 Hall EJ and Giaccia AJ: Radiobiology for the Radiologist. Seventh edition. Philadelphia: Lippincott, Williams, and Wilkins Company, pp. 86-103, 2012.
Received April 17, 2021

Revised May 6, 2021

Accepted May 7, 2021 